\title{
A utilização da posição prona no recém-nascido pré termo e lactente submetido a ventilação mecânica em casos de bronquiolite viral aguda
}

\author{
The use of the prone position in the preterm newborn and infant submitted to mechanical \\ ventilation in cases of acute viral bronchiolitis
}

El uso de la posición prona en el recién nacido pretérmino y el lactante sometido a ventilación mecánica en casos de bronquiolitis viral aguda

\section{Resumo}

Introdução: A bronquiolite viral aguda é uma doença respiratória que causa obstrução das vias áreas inferiores, levando à dificuldade respiratória, mais frequente em neonatos, lactentes e crianças até três anos de idade, com predominância nos seis primeiros meses de vida. Seu principal agente etiológico é o vírus sincicial respiratório presente em $75 \%$ dos casos de hospitalização. Objetivo: Analisar a eficácia do uso da ventilação mecânica associada a posição prona em lactentes com bronquiolite viral aguda. Metodologia: Trata-se de uma revisão narrativa de literatura, com pesquisa de artigos científicos em bases de dados online, publicados entre 2015 e 2020, nos idiomas Português, Espanhol, Inglês, Italiano e Francês. Resultados: Foram encontrados 1.215 artigos, os mesmos foram analisados através de uma adaptação da tabela de Strobe, dos quais, 7 foram incluídos na discussão. Conclusão: Foi possível constatar a eficácia da posição prona associada a ventilação mecânica em lactantes e com bronquiolite viral aguda, melhorando tanto a eficácia respiratória quanto cardíaca, diminuindo o tempo de suporte ventilatório no lactente.

Palavras-chave: Decúbito ventral; Bronquiolite viral; Respiração artificial; Pediatria.

\begin{abstract}
Introduction: Acute viral bronchiolitis is a respiratory disease that causes obstruction of the lower airways, leading to respiratory distress, more frequent in neonates, infants and children up to three years of age, with predominance in the first six months of life. Its main etiological agent is the respiratory syncytial virus present in $75 \%$ of hospitalization cases. Objective: To analyze the effectiveness of using mechanical ventilation associated with the prone position in infants with acute viral bronchiolitis. Methodology: It is a narrative review of literature, with research of scientific articles in online databases, published between 2015 and 2020, in Portuguese, Spanish, English, Italian and French. Results: 1,215 articles were found, they were analyzed through an adaptation of the Strobe table, of which, 7 were included in the discussion. Conclusion: It was possible to verify the effectiveness of the prone position associated with mechanical ventilation in lactating women and with acute viral bronchiolitis, improving both respiratory and cardiac efficacy, decreasing the time of ventilatory support in the infant.
\end{abstract}

Keywords: Prone position; Viral bronchiolitis; Artificial respiration; Pediatrics.

\section{Resumen}

Introducción: La bronquiolitis viral aguda es una enfermedad respiratoria que ocasiona obstrucción de las vías respiratorias inferiores, dando lugar a distrés respiratorio, más frecuente en neonatos, lactantes y niños hasta los tres 
años de edad, con predominio en los primeros seis meses de vida. Su principal agente etiológico es el virus respiratorio sincitial presente en el $75 \%$ de los casos de hospitalización. Objetivo: Analizar la efectividad del uso de ventilación mecánica asociada a la posición prona en lactantes con bronquiolitis viral aguda. Metodología: Se trata de una revisión narrativa de la literatura, con búsqueda de artículos científicos en bases de datos en línea, publicados entre 2015 y 2020 , en portugués, español, inglés, italiano y francés. Resultados: Se encontraron 1.215 artículos, se analizaron mediante una adaptación de la tabla Strobe, de los cuales, 7 fueron incluidos en la discusión. Conclusión: se pudo verificar la efectividad de la posición de decúbito prono asociada a la ventilación mecánica en mujeres lactantes y con bronquiolitis viral aguda, mejorando la eficacia tanto respiratoria como cardíaca, disminuyendo el tiempo de soporte ventilatorio en el lactante.

Palabras clave: Decúbito prono; Bronquiolitis viral; Respiración artificial; Pediatria.

\section{Introdução}

A Bronquiolite Viral Aguda (BVA) é uma doença respiratória que causa obstrução das vias áreas inferiores levando à dificuldade respiratória, acomete prioritariamente neonatos, lactentes e crianças até três anos de idade, com predomínio nos seis primeiros meses de vida. Possui característica sazonal ocorrendo epidemicamente nos meses de outono e inverno, seu principal agente etiológico é o vírus sincicial respiratório (VSR) presente em 75\% dos casos de hospitalização (Carrascoza, Abreu, Araujo \& Torres, 2019); Universidade Federal do Triângulo Mineiro (UFTM), Empresa Brasileira de Serviços Hospitalares (EBSERH), Ministério da Educação (2016).

Nos Estados Unidos ocorrem aproximadamente 100 mil admissões ambulatoriais por BVA anualmente, a taxa média de hospitalização pelo VSR foi de 5,2 a cada 1.000 crianças, em pacientes com menos de 24 meses de idade, durante o período de 5 anos (2000 a 2005). A maior taxa classificada por idade de hospitalização por VSR ocorreu em lactentes entre 30 e 60 dias de idade, sendo 25,9 a cada 1.000 crianças hospitalizadas. (Ralston, Lieberthal, Meissner, Alverson, Baley, Gadomski et al 2014).

O VSR é altamente contagioso sendo propagado através do contato com as secreções, o contágio no ambiente escolar e familiar são muito elevados, e em ambientes hospitalares pode ser facilmente disseminado. Os sintomas característicos da BVA envolvem febre, congestão nasal, tosse, taquipneia ou dispneia, tiragem intercostais e batimento de aletas nasais; na ausculta pulmonar estão presentes estertores e chiados expiratórios. A apneia pode ser uma manifestação precoce na infecção por VSR, podendo resultar em insuficiência respiratória exigindo cuidados intensivos e ventilação mecânica (VM) (EBSERH 2016; Meissner 2018).

A VM é utilizada nas unidades de terapia intensiva pediátrica (UTIP) como estratégia no manejo de pacientes com insuficiência respiratória aguda ou crônica, tendo como objetivo a manutenção das trocas gasosas, reparando a hipoxemia e a hipercapnia, impedindo a fadiga da musculatura respiratória, além de minimizar os índices de morbidade e mortalidade. Algumas estratégias terapêuticas são usadas junto à VM, como a posição prona (PP) (Andreolio 2018; Fioretto, Klefens, Pires, Kurokawa, Carpi, Bonatto, et al 2017; Rosário, Callegari, Souza, Tropiano \& Fernandes 2017).

O decúbito ventral, também conhecido como posição prona, consiste no posicionamento do lactente de maneira a manter o suporte diafragmático e estabilização da caixa torácica constantes, através do contínuo contato da caixa torácica e do abdome com o leito. A PP auxilia na melhora da oxigenação durante a VM, promovido pelo aumento do volume pulmonar, melhorando a mobilidade de secreções, reexpandindo alvéolos e redistribuindo sua ventilação, expandindo a região dorsal dos pulmões e diminuindo as chances de atelectasia (Benjamin, Santos, Salvador \& Jorge 2018; Paiva \& Beppu 2005; Panhoni, Martins, Fernandes, Callegari, Moraes, de Salerno \& Tropiano 2019).

O objetivo deste estudo foi realizar uma revisão de literatura analisando artigos publicados entre os anos de 2015 a 2020 sobre a eficácia do uso da ventilação mecânica associada a posição prona, em lactentes com Bronquiolite Viral Aguda. 


\section{Metodologia}

Este estudo foi realizado através de buscas nas bases de dados online PubMed, PEDro, Cochrane Library, Cience Direcet, Elsevier, Scielo, Lilacs, Swiss Medical Forum e BMJ Brasil, publicados entre os anos de 2015 e 2020, nos idiomas português, espanhol, inglês, italiano e francês.

A pesquisa foi realizada a partir das palavras-chave e operadores booleanos: ("acute viral bronchiolitis" OR "viral acute bronchiolitis" OR "bronchiolitis viral acute" OR "bronchiolitis acute viral” OR "respiratory sinus virus" OR "virus sinus respiratory" OR “sinus respiratory virus" OR "respiratory virus sinus" OR “preterm newborn”) AND ("infants" OR “admitted” OR "pediatric intensive care unit" OR “neonatal intensive care unit" OR "use mechanical ventilation" OR "mechanical ventilation use") AND (“prone position" OR “position prone” OR “treatment”).

No caso específico da base de dados latino-americana SciELO, foram utilizadas as seguintes palavras-chave e operadores booleanos para pesquisar artigos em português: ("bronquiolite viral aguda”) OR ("bva”) OR ("vírus sincicial respiratório") OR (“vsr”) AND (“ventilação mecânica”) OR (“vm”) AND (“posição prona”) OR (“decúbito dorsal”). Os autores e a lista de referências dos artigos foram consultados adicionalmente.

Foram incluídos artigos que relatassem casos de BVA por VSR em recém nascidos pré termo (RNPT) e lactentes, admitidos em UTIP e Unidade de terapia intensiva neonatal (UTIN), em uso de VM e/ou posição prona como forma de tratamento. Foram excluídos artigos que não relatavam casos de BVA por VSR, artigos que mencionavam outra população além de RNPT e lactentes e estudos que não utilizassem VM e/ou PP como forma de tratamento. A revisão analisou os trabalhos incluídos de forma qualitativa.

Os critérios de elegibilidade foram:

- $\quad$ Patologia base: BVA pelo agente etiológico VSR;

- $\quad$ População estudada: lactantes e/ou RNPT;

- Utilizar a PP e/ou VM como tratamento;

- $\quad$ Não ser um estudo envolvendo animais.

\section{Resultados}

A pesquisa inicial realizada identificou 1.215 artigos, a qual foi realizada uma análise criteriosa dos artigos identificados, exclusão dos trabalhos repetidos e leitura do conteúdo completo, sendo foi feita uma nova seleção com base nos critérios de inclusão, totalizando 35 artigos.

Para analisar a qualidade dos artigos foi utilizada uma adaptação da lista de verificação de STROBE (Barbosa, Romanzini, Batista, Fernandes, Romanzini, Kemper et al 2020; von Elm, Altman, Egger, Pocock, Gøtzsche, Vandenbroucke \& STROBE Initiative 2007), uma ferramenta que tem como objetivo contribuir com a análise de estudos observacionais através de recomendações sobre quais informações devem conter no título, resumo, introdução, metodologia, resultados e discussão, auxiliando na relevância e interpretação dos dados, e facilitando a leitura crítica destas publicações. Os itens avaliados na adaptação da lista de STROBE foram listados na Tabela 1. 
Tabela 1 - Itens avaliados pela adaptação da Lista de Strobe.

\begin{tabular}{|c|c|}
\hline & Adaptação da Lista de Strobe \\
\hline Itens & Recomendações \\
\hline 1 & $\begin{array}{l}\text { Título e Resumo: indicar no título e/ou resumo informações do que foi realizado na pesquisa, } \\
\text { descrevendo uma prévia do que foi realizado no estudo e pelo menos uma palavra-chave utilizada na } \\
\text { pesquisa, resumir os principais achados relacionando-os aos objetivos do estudo. }\end{array}$ \\
\hline 2 & $\begin{array}{l}\text { Justificativa: detalhar as razões para a execução da pesquisa, descrevendo os objetivos gerais e } \\
\text { específicos, incluindo quaisquer hipóteses pré-estabelecidas. }\end{array}$ \\
\hline 3 & $\begin{array}{l}\text { Métodos: descrever o contexto, locais, datas, incluindo os períodos de recrutamento, acompanhamento } \\
\text { (follow-up) e coleta de dados. }\end{array}$ \\
\hline 4 & $\begin{array}{l}\text { Métodos: Estudos de coorte: apresentar os critérios de elegibilidade, métodos de seleção dos } \\
\text { participantes e tipo de acompanhamento. } \\
\text { Estudos controle: descrever os critérios de elegibilidade, critério-diagnóstico para identificação dos } \\
\text { casos e os métodos de seleção. }\end{array}$ \\
\hline 5 & $\begin{array}{l}\text { Métodos: Estudos de Coorte: descrever o período de acompanhamento, número de eventos ou as } \\
\text { medidas ao longo do tempo. } \\
\text { Caso - Controle: descrever o número de indivíduos em cada categoria de exposição ou apresentar } \\
\text { medidas de exposição. } \\
\text { Estudos Seccionais: descrever o número de eventos-desfecho ou apresentar as medidas. }\end{array}$ \\
\hline 6 & $\begin{array}{l}\text { Variáveis: definir todos os desfechos, exposições, preditores, confundidores e modificadores (quando } \\
\text { necessário), apresentar os critérios diagnósticos. Para cada variável de interesse, descrever a fonte dos } \\
\text { dados e os detalhes dos métodos utilizados na mensuração. Caso exista mais de um grupo, descrever a } \\
\text { comparação dos métodos de avaliação. }\end{array}$ \\
\hline 7 & $\begin{array}{l}\text { Variáveis: especificar todas as medidas adotadas para evitar potenciais fontes de viés, como se } \\
\text { determinou o tamanho da amostra e como foram tratadas as variáveis quantitativas na análise. }\end{array}$ \\
\hline 8 & $\begin{array}{l}\text { Variáveis: descrever todos os métodos e estatísticas utilizados, número de participantes em cada etapa } \\
\text { do estudo, características dos participantes, informações sobre exposições e confundidores em } \\
\text { potencial. }\end{array}$ \\
\hline 9 & Variáveis: descrever outras análises que tenham sido realizadas. \\
\hline 10 & $\begin{array}{l}\text { Resultados: apresentar as limitações do estudo, levando em consideração fontes potenciais de viés ou } \\
\text { imprecisão. }\end{array}$ \\
\hline 11 & $\begin{array}{l}\text { Resultados: apresentar uma interpretação dos resultados, considerando os objetivos, limitações, } \\
\text { multiplicidade das análises, resultados de estudos semelhantes e outras evidências relevantes. }\end{array}$ \\
\hline 12 & $\begin{array}{l}\text { Discussão: discutir os principais resultados do estudo, interpretação geral, resultados de estudos } \\
\text { similares e expondo os principais resultados estudados. }\end{array}$ \\
\hline 13 & $\begin{array}{l}\text { Financiamento: especificar a fonte de financiamento do estudo e o papel dos financiadores (se } \\
\text { houver). }\end{array}$ \\
\hline
\end{tabular}

Fonte: Tabela elaborada pelos autores segundo a Lista de Strobe.

A avaliação da adaptação da lista de Strobe consistiu em pontuar os trabalhos de acordo com a existência, ou não, dos pontos avaliados, com pontuação máxima de 13 pontos. Os artigos que receberam pontuação entre 0 e 4 foram considerados de baixa qualidade, de 5 a 8 pontos foram considerados de moderada qualidade e pontuações entre 9 a 13 foram consideradas de alta qualidade (Barbosa et al 2020).

Sete estudos obtiveram classificação de qualidade moderada e alta, e foram incluídos na discussão. As demais pesquisas pontuaram entre 3 e 4, e, portanto, foram excluídas desta revisão. A pontuação dos estudos incluídos de acordo com a adaptação da lista Strobe encontra-se na Tabela 2. 
Tabela 2 - Pontuação dos estudos classificados como moderada e alta qualidade, incluídos nesta revisão.

\begin{tabular}{l|c|c|c|c|c|c|c|c|c|c|c|c|c|c}
\hline Tabela de Strobe & $\mathbf{1}$ & $\mathbf{2}$ & $\mathbf{3}$ & $\mathbf{4}$ & $\mathbf{5}$ & $\mathbf{6}$ & $\mathbf{7}$ & $\mathbf{8}$ & $\mathbf{9}$ & $\mathbf{1 0}$ & $\mathbf{1 1}$ & $\mathbf{1 2}$ & $\mathbf{1 3}$ & Total \\
\hline Ferlini R, et al (2015). & 1 & 0 & 1 & 1 & 1 & 0 & 1 & 1 & 1 & 0 & 1 & 1 & 0 & 9 \\
\hline Hough J, et al (2016). & 1 & 0 & 1 & 1 & 1 & 0 & 0 & 1 & 1 & 0 & 1 & 1 & 0 & 8 \\
\hline Fernandez JMR, et al (2017). & 1 & 0 & 1 & 1 & 1 & 1 & 0 & 1 & 0 & 0 & 1 & 1 & 0 & 8 \\
\hline Queiroz CMB, et al (2017). & 1 & 0 & 1 & 1 & 1 & 0 & 0 & 1 & 1 & 0 & 1 & 1 & 0 & 8 \\
\hline Baudin MDF, et al (2019). & 1 & 1 & 1 & 1 & 0 & 0 & 0 & 1 & 0 & 0 & 1 & 1 & 0 & 7 \\
\hline Medeiros MCS (2019). & 1 & 0 & 1 & 1 & 0 & 0 & 0 & 1 & 1 & 0 & 1 & 1 & 0 & 7 \\
\hline Gomes ELFD, et al (2019). & 1 & 0 & 1 & 1 & 0 & 1 & 0 & 1 & 0 & 0 & 1 & 1 & 0 & 7 \\
\hline
\end{tabular}

Fonte: Autores.

O processo de seleção dos artigos incluídos nesta revisão pode ser observado no diagrama abaixo (Figura 1):

Figura 1 - Diagrama do processo de seleção dos artigos.

Busca nas bases de dados

PubMed: 5;

PEDro: 26;

Cochrane Library: 13;

Cience Direct: 1114;

Elsevier: 44;

Scielo: 12;

Swiss Medical Forum: 1.
7 artigos incluidos para a discussão.
Artigos classificados de acordo com a adaptação da

Lista de

STROBE
Artigos encontrados:

1.215
Exclusão por análise de título e leitura do contéudo.

Fonte: Diagrama elaborado pelos autores.

Na Tabela 3 pode-se observar os artigos incluídos na discussão, sendo 2 artigos na língua inglesa, 1 na língua espanhola e 4 na língua portuguesa. 
Tabela 3 - Artigos incluídos para a discussão.

\begin{tabular}{|c|c|c|c|}
\hline Autores/Ano & Tipo de estudo & Objetivos e Intervenção & Resultados \\
\hline Ferlini et al (2015). & $\begin{array}{l}\text { Estudo longitudinal, com } \\
66 \text { lactentes menores de } 1 \\
\text { ano. }\end{array}$ & $\begin{array}{l}\text { Analisar características de } \\
\text { lactentes com BVA submetidos à } \\
\text { VM em } 3 \text { anos consecutivos, } \\
\text { relacionando a evolução com os } \\
\text { parâmetros de ventilação } \\
\text { mecânica e o balanço hídrico. }\end{array}$ & $\begin{array}{l}\text { Tiveram aumento de } 10 \% \text { no peso } \\
37 \text { pacientes }(56 \%) \text {, sem associação } \\
\text { significativa aos parâmetros } \\
\text { ventilatórios no } 4^{\circ} \text { dia de VM, falha } \\
\text { de extubação ou tempo de VM e na } \\
\text { UTIP. }\end{array}$ \\
\hline Hough et al (2016). & $\begin{array}{lr}\text { Estudo } & \text { cruzado } \\
\text { randomizado } & \text { com } 60 \\
\text { RNPT. } & \end{array}$ & $\begin{array}{l}\text { Investigar as mudanças da função } \\
\text { pulmonar em RNPT em um } \\
\text { período de } 12 \text { horas, estudados em } \\
3 \text { grupos: VM, CPAP nasal e } \\
\text { ventilação espontânea, e } \\
\text { colocados em } 3 \text { decúbitos: supino, } \\
\text { prono com a cabeça para o lado } \\
\text { direito e para o lado esquerdo. }\end{array}$ & $\begin{array}{l}\text { A mudança na posição corporal } \\
\text { proporciona a melhora na função } \\
\text { pulmonar em bebês com suporte } \\
\text { ventilatório. }\end{array}$ \\
\hline Baudin et al (2019). & $\begin{array}{lrr}\text { Estudo rruzado } & r \\
\text { randomizado de } & 16 \\
\text { lactentes do } & \text { sexo } \\
\text { masculino, com } & \text { idade } \\
\text { média de } 3 & \text { meses, } \\
\text { diagnosticados com BVA. }\end{array}$ & $\begin{array}{l}\text { Relatar o efeito da PP e PS nas } \\
\text { medidas fisiológicas: esforço } \\
\text { inspiratório, custo metabólico da } \\
\text { respiração e impulso neural para o } \\
\text { diafragma, em lactentes com BVA } \\
\text { que requerem VNI. }\end{array}$ & $\begin{array}{l}\text { Este estudo sugere um benefício da } \\
\text { PP para bebês com bronquiolite } \\
\text { grave que requerem VNI, } \\
\text { diminuindo significativamente o } \\
\text { esforço inspiratório e o custo } \\
\text { metabólico da respiração. }\end{array}$ \\
\hline $\begin{array}{l}\text { Fernandez et al } \\
(2017) .\end{array}$ & $\begin{array}{l}\text { Estudo retrospectivo de } \\
\text { pacientes menores de } 6 \\
\text { meses internados por } \\
\text { BVA por VSR. }\end{array}$ & $\begin{array}{l}\text { Determinar as admissões em UTIP } \\
\text { por VM de pacientes com BVA } \\
\text { menores de } 6 \text { meses e definir os } \\
\text { fatores de risco. }\end{array}$ & $\begin{array}{l}\text { Dos } 695 \text { casos, } 56 \quad(8,1 \%) \\
\text { necessitaram de VM na UTIP. Os } \\
\text { fatores de risco incluídos foram: } \\
\text { Sexo masculino }(4,27) \text {, idade pós- } \\
\text { menstrual }(0,76) \text {, peso na admissão } \\
(5,53) \text { ingestão <50\% }(12,4) \text {, } \\
\text { gravidade por escala }(1,58) \text {, apnéias } \\
\text { antes da admissão }(25,5) \text {, } \\
\text { superinfecção bacteriana }(5,03) \text { e } \\
\text { idade gestacional > } 37 \text { semanas } \\
(0,32) \text {. }\end{array}$ \\
\hline Queiroz et al (2017). & $\begin{array}{l}\text { Pesquisa intervencionista, } \\
\text { amostra de } 20 \text { RNPT } \\
\text { internados na UTIN. }\end{array}$ & $\begin{array}{l}\text { Verificar a utilização das redes de } \\
\text { descanso e do PP no alívio da dor } \\
\text { e no comportamento dos sinais } \\
\text { vitais em RNPT. }\end{array}$ & $\begin{array}{l}\text { Foi observada melhora significativa } \\
\text { nos sinais vitais e na dor em ambos } \\
\text { os posicionamentos, indicando que } \\
\text { as duas alterações obtiveram } \\
\text { resultados semelhantes nos RN. }\end{array}$ \\
\hline Medeiros (2019). & $\begin{array}{l}\text { Estudo do tipo Linking } \\
\text { Evidence and Practice } \\
\text { (revisão de } 13 \text { estudos). }\end{array}$ & $\begin{array}{l}\text { Destacar os principais resultados } \\
\text { de uma revisão sistemática } \\
\text { (Cochrane) orientando para uma } \\
\text { prática segura e eficaz. Apresenta } \\
\text { recomendações relevantes sobre a } \\
\text { tomada de decisão clínica diante } \\
\text { da descrição de um caso clínico. }\end{array}$ & $\begin{array}{l}\text { Dos } 13 \text { estudos que compararam PP } \\
\text { versus PS, verificou-se que a PP } \\
\text { melhora a pressão parcial de } \\
\text { oxigênio }\left(\mathrm{PaO}_{2}\right) \text { e a saturação de } \\
\text { oxigênio }\left(\mathrm{SpO}_{2}\right) \text {. }\end{array}$ \\
\hline Gomes et al (2019). & $\begin{array}{l}\text { Estudo quase } \\
\text { experimental de 50 RNPT }\end{array}$ & $\begin{array}{l}\text { Avaliar as respostas fisiológicas e } \\
\text { do sistema nervoso autônomo de } \\
\text { RNPT ao posicionamento do } \\
\text { corporal e ruídos ambientais na } \\
\text { UTIN. }\end{array}$ & $\begin{array}{l}\text { A PP e a posição com restrição } \\
\text { manual aumentaram tanto a } \\
\text { atividade parassimpática quanto a } \\
\text { complexidade dos ajustes } \\
\text { autonômicos em comparação com a } \\
\text { PS, mesmo na presença de ruído } \\
\text { ambiental maior do que o nível } \\
\text { recomendado. }\end{array}$ \\
\hline
\end{tabular}

Legenda da tabela: BVA: bronquiolite viral aguda; VM: ventilação mecânica; UTIP: unidade de terapia intensiva pediátrica; UTIN: unidade de terapia intensiva neonatal; RN: recém-nascido; RNPT: recém-nascido pré termo; CPAP: pressão positiva contínua nas vias aéreas; PP: posição prona; PS: posição supina; VNI: ventilação não invasiva; VSR: vírus sincicial respiratório. Fonte: Dados dos artigos analisados. 


\section{Discussão}

No estudo longitudinal de Ferlini, Pinheiro, Andreolio, Carvalho e Piva (2015) foram analisadas as características de 66 crianças, menores de um 1 ano de idade com BVA submetidas à VM em 3 anos consecutivos (janeiro de 2012 a setembro de 2014), comparando sua evolução com os parâmetros da VM e do balanço hídrico. O balanço hídrico cumulativo aumentou no $4^{\circ}$ dia de VM, correspondendo a um aumento no peso em $10 \%$ dos pacientes (37 pacientes), sem associação significativa aos parâmetros ventilatórios no $4^{\circ}$ dia de VM, falha de extubação ou tempo de VM e internação em UTIP. O tempo médio de VM foi 6,5 \pm 2,9 dias, tempo de UTIP de 9,1 \pm 3,5 dias, com mortalidade de 1,5\% (1/66). O pico de pressão inspiratória médio manteve-se em 30cmH2O nos 4 primeiros dias de VM, reduzindo-se na pré-extubação $(25 \mathrm{cmH} 2 \mathrm{O}$; p < 0,05). Como resultado, pode-se observar que, a taxa de utilização da VM na BVA se manteve constante auxiliando na diminuição da mortalidade, com poucos efeitos adversos, e, associada a melhora do balanço hídrico nos primeiros dias, pode reduzir o tempo de VM minimizando os efeitos adversos desse mecanismo.

Hough, Trojman e Schibler (2016) realizaram um estudo com 60 RNPT medindo as mudanças na função pulmonar ocorridas após o reposicionamento dos pacientes em um período de 12 horas, divididos em 3 grupos: VM, Continuous Positive Airway Pressure (CPAP) nasal e respiração espontânea. Os bebês foram alocados aleatoriamente quanto a 3 posições corporais diferentes (supino, prono com a cabeça virada para a direita e prona com a cabeça virada para a esquerda), essas mudanças ocorreram a cada 4 horas (totalizando 12 horas). As mudanças no nível expiratório final (EEL) e distribuição da ventilação foram mensuradas 30 minutos, 2 horas e 4 horas após o posicionamento, usando Tomografia de Impedância Elétrica (TIE), além da avaliação das medidas fisiológicas. Bebês em VM ou CPAP mostraram melhora na homogeneidade da ventilação após 2 horas na postura, bebês com respiração espontânea melhoraram a homogeneidade em 2 horas de postura e melhoraram EEL global após 4 horas, enquanto bebês que receberam CPAP demonstraram uma melhor EEL global em 2 horas de postura; corroborando a este estudo, mostrando que a mudança na posição do corpo traz uma melhora na função pulmonar em bebês com suporte ventilatório.

Baudin, Emeriaud, Essouri, Beck, Portefaix, Javouhey e Guerin (2019) avaliaram o efeito da PP nas medidas fisiológicas (esforço inspiratório, custo metabólico da respiração e impulso neural para o diafragma), em comparação com a PS em bebês com bronquiolite grave que necessitaram do uso de ventilação não invasiva (VNI). Participaram do estudo 14 lactentes, com idade mediana de 33 dias, randomizados para receber pressão positiva contínua de $7 \mathrm{cmH} 2 \mathrm{O}$ nas vias aéreas por 1 hora na PP ou PS. Como resultado pode-se observar que em todas as medidas (mecânicas, neurais e clínicas), a respiração era mais fácil na PP do que na PS. Com relação à função do diafragma, houve um aumento da razão transdiafragmática na PP. Corroborando com os dados de Hough et al (2016), que apontam que a PP pode ser particularmente benéfica em bebês com maior esforço na PS.

Fernández, Pérez, Bedmar, Yuste, Martínez, Manso e Cardona (2017) realizaram um estudo retrospectivo de 695 casos de lactentes menores de 6 meses internados por BVA por VSR (1 de abril de 2010 a 31 de março de 2015). A variável primária foi a admissão na UTIP para uso de VM, dos quais 56 lactentes necessitaram de VM $(8,1 \%)$. Os fatores de risco incluídos na equação foram: sexo masculino (OR 4,27), idade pós-menstrual (OR: 0,76), renda ponderal <p3 (OR: 5,53), ingestão <50\% (OR: 12,4), gravidade por escala (OR: 1,58), apneias antes da admissão (OR: 25,5), superinfecção bacteriana $($ OR 5,03$)$ e idade gestacional > 37 semanas (OR: 0,32). O estudo mostrou que a admissão na UTIP para uso de VM foi de 8,1 em cada 100 lactentes saudáveis internados por BVA no ano. O modelo de previsão pode ajudar a prever pacientes com risco aumentado de evolução grave da bronquiolite que podem necessitar de uso da VM.

Queiroz et al (2017) realizaram uma pesquisa intervencionista, com 20 RNPT de ambos os sexos internados em UTIN, onde verificou-se a utilização de redes de descanso e da PP no alívio da dor e na variação dos sinais vitais em RNPT, avaliando dor, frequência cardíaca (FC), frequência respiratória (FR), pressão arterial média (PAM), saturação de oxigênio (SpO2) e temperatura corporal (TAX). Os RNs foram submetidos ao posicionamento em prono, com auxílio de coxins de tecido em forma 
de rolo para elevar o tórax e facilitar a dinâmica diafragmática. A cabeça do RNPT foi lateralizada e alinhada ao tronco, posicionando os membros superiores e inferiores em flexão e as mãos próximas à face, durante 40 minutos. Em seguida foi realizado o posicionamento nas redes de descanso, técnica em que o recém-nascido simula a posição uterina flexora e alinhada, suspenso pela rede colocada na incubadora, sem contato com colchão, durante 40 minutos. Após as intervenções foi possível identificar que o posicionamento em prono e rede de descanso promoveu melhora na SpO2 e na dor. Estes achados alertam para a importância das mudanças de decúbito (prono e rede de descanso) em RNPT estáveis internados em UTIN, por se tratarem de métodos não invasivos e de baixo custo que proporcionam benefícios para o seu desenvolvimento e minimizam os prejuízos resultantes da exposição ao estresse.

Medeiros (2019) realizou um estudo do tipo Linking Evidence and Practice (revisão de 13 estudos), com a finalidade de destacar os principais resultados de uma revisão sistemática (Cochrane) orientando para uma prática segura e eficaz. Os estudos compararam a posição prona e supino, e verificaram que a posição prona melhora a pressão parcial de oxigênio $(\mathrm{PaO} 2)$ e a SpO2. Em relação a mecânica pulmonar em respiração espontânea e índice de oxigenação ( $\mathrm{PaO} 2 / \mathrm{FiO} 2)$, não foram encontradas diferenças significativas. O estudo auxilia na tomada de decisão clínica, através de informações consistentes que orientam uma prática segura e baseada em evidência, além do que elimina o paradigma que recém-nascidos em UTIN devam permanecer exclusivamente em decúbito dorsal.

Gomes et al (2019) avaliaram as respostas fisiológicas e do sistema nervoso autônomo de RNPT comparados ao posicionamento do corpo e de ruídos ambientais na UTN. O estudo foi do tipo prospectivo quase-experimental, com um único grupo de recém-nascidos, no qual cada criança serviu como próprio controle para cada posição. Cinquenta RNPT foram avaliados (idade gestacional de 32,6 $\pm 2,3$ semanas; peso de $1.816 \pm 493 \mathrm{~g}$ ) e identificou-se uma correlação positiva entre o ruído ambiental e a atividade simpática $(R=0,27 ; p=0,04)$. O ruído ambiental médio foi de $53 \pm 14 \mathrm{~dB}$ e a $\mathrm{FC}$ foi mais elevada na posição supina, quando comparada as posições com restrição manual e prona $(148,7 \pm 21,6 ; 141,9 \pm 16$ e $144 \pm 13$, respectivamente; $p$ $=0,001)$. A atividade simpática, representada por um índice de baixa frequência, foi mais elevada na posição supina $(\mathrm{p}<0,05)$ do que nas demais posições, e a atividade parassimpática (alta frequência, raiz quadrada da média dos quadrados das diferenças entre os intervalos RR normais adjacentes e porcentagem dos intervalos $R-R$ adjacentes com diferença de duração maior que $50 \mathrm{~ms})$ foi mais elevada na posição prona $(\mathrm{p}<0,05)$ do que nas demais posições. A complexidade dos ajustes autonômicos (entropia aproximada e entropia da amostra) foi mais baixa na posição supina do que nas demais posições. A posição prona e a restrição manual para recém-nascidos prematuros aumentaram tanto a atividade parassimpática quanto a complexidade dos ajustes autonômicos, quando comparados com a posição supina, mesmo na presença de maior nível de ruídos ambientais, que tende a aumentar a atividade simpática.

\section{Conclusão}

A posição prona associada a ventilação mecânica, em lactantes e com bronquiolite viral aguda, melhora tanto a eficácia respiratória quanto cardíaca, diminuindo o tempo de suporte ventilatório no lactente. Estes achados alertam para a importância das mudanças de decúbito em lactantes estáveis internados em UTIN, por se tratar de um método não invasivo e de baixo custo, que proporciona benefícios para o seu desenvolvimento e minimiza os prejuízos resultantes da utilização prolongada da ventilação mecânica.

A literatura possui poucos artigos e publicações recentes relacionados ao tema, esperamos que este trabalho possa contribuir para que profissionais da fisioterapia possam se interessar e se aprofundar em novos estudos e pesquisas relacionados ao assunto. Sendo assim, sugerimos a realização de mais estudos sobre este tema, afim de mostrar a importância da mudança de decúbito em diversos desfechos e patologias na população neonatal e pediátrica. 


\section{Referências}

Andreolio, C. (2018). Propriedades da mecânica respiratória em crianças com bronquiolite viral aguda em ventilação mecânica. Universidade Federal do Rio Grande do Sul. http://hdl.handle.net/10183/196651

Baudin, F., Emeriaud, G., Essouri, S., Beck, J., Portefaix, A., Javouhey, E., \& Guerin, C. (2019). Physiological Effect of Prone Position in Children with Severe Bronchiolitis: A Randomized Cross-Over Study (BRONCHIO-DV). The Journal of pediatrics, 205, 112-119.e4. 10.1016/j.jpeds.2018.09.066.

Barbosa, C. C.S., et al (2020). Aptidão neuromuscular na juventude e o impacto na saúde óssea na idade adulta: uma revisão sistemática. Revista paulista de pediatria, 38, e2019119.

Benjamin, M. F., Santos, A. C., Salvador, A. C. \& Jorge, M. A. (2018). Posição prona em unidade de terapia intensiva. Revista UNILUS Ensino e Pesquisa, 15 (40) 77. ISSN 2318-2083. http://revista.unilus.edu.br/index.php/ruep/article/view/977

Carrascoza, G. G., Abreu, L. A., Araujo, L. U. \& Torres, F. Q. (2019). Bronquiolite Viral Aguda e o uso de Imunoprofilaxia com Palivizumabe. Brazilian Journal of Surgery and Clinical Research. Master Editora, 27, (3) 71-74. https://www.mastereditora.com.br/periodico/20190805_074056.pdf

Ferlini, R., Pinheiro, F. O., Andreolio, C., Carvalho, P. R. A. \& Piva, J. P. (2015). Características e evolução de crianças com bronquiolite viral aguda submetidas à ventilação mecânica. Revista Brasileira Terapia Intensiva, 28 (1), 55-61. https://doi.org/10.5935/0103-507X.20160003

Fioretto J. R., et al (2017). Comparação entre ventilação mecânica convencional protetora e ventilação oscilatória de alta frequência associada à posição prona. Revista Brasileira de Terapia Intensiva, 29 (4) (p. 427-435). https://doi.org/10.5935/0103-507X.20170067

Gomes, E. L. F. D., et al (2019). Respostas autonômicas de recém-nascidos prematuros ao posicionamento do corpo e ruídos ambientais na unidade de terapia intensiva neonatal. Revista Brasileira de Terapia Intensiva. Universidade Nove de Julho. São Paulo, SP, Brasil, 31 (3), 296-302. https://doi.org/10.5935/0103507X.20190054

Hough, J., Trojman, A., \& Schibler, A. (2016). Effect of time and body position on ventilation in premature infants. Pediatric research, 80(4), 499-504. https://doi.org/10.1038/pr.2016.116

Medeiros, M. C. S. (2019). Influência do posicionamento no recém-nascido em ventilação mecânica, vinculando Evidências e Práticas. Universidade federal do Rio Grande do Norte. Escola Multicampi de Ciências Médicas. Residência multiprofissional em saúde materno infantil, (p. 1-32). http://monografias.ufrn.br/handle/123456789/10378

Meissner, H. C. (2014). Bronquiolite: Princípios e práticas de doenças infecciosas pediátricas. Pediatrics, 134 (5). https://pediatrics.aappublications.org/content/134/5/e1474.long

Paiva, K. C. A. \& Beppu, O. S. (2005). Posição Prona. Jornal Brasileiro de Pneumologia, 31 (4), 332-340. https://doi.org/10.1590/S1806-37132005000400011

Panhoni, D. A., Martins, F. P. A., Fernandes, M., Callegari, M. R., Moraes, I. A. P., de, Salerno, G. R. F. \& Tropiano, L. M. C. C. (2019). Conhecimento de profissionais da saúde sobre o posicionamento do recém-nascido prematuro em Unidade de Terapia Intensiva Neonatal. Cadernos de Pós-Graduação em Distúrbios do Desenvolvimento, 19(2), 84-102. https://dx.doi.org/10.5935/cadernosdisturbios.v19n2p84-102

Pereira A. S. et al. (2018). Metodologia da pesquisa científica. UFSM.

Queiroz, C. M. B., et al (2017). Repercussões no neonato da utilização de redes de descanso e posição prono. Revista de Investigação Biomédica de São Luís, 9 (2) (p.159-167). http://www.ceuma.br/portalderevistas/index.php/RIB/article/view/127/0

Fernández, J. M. R., Pérez, M. D., Bedmar, G. M., Yuste, H. A., Martínez, C. M. A., Manso, M. G., \& Cardona, U. A. (2017). Predicción de la evolución de la bronquiolitis por virus respiratorio sincitial en lactantes menores de 6 meses. Revista Española de Salud Pública, Vol. 91 ; 19 de enero e1-e8. http://scielo.isciii.es/scielo.php?script=sci_arttext\&pid=S1135-57272017000100401\&lng=es\&tlng=es

Ralston, S. L., et al (2014). Clinical practice guideline: the diagnosis, management, and prevention of bronchiolitis. Pediatrics, 134(5), e1474-e1502. https://doi.org/10.1542/peds.2014-2742

Rosário, I. F., Callegari, M. R., Souza, A. C., Tropiano, L. M. C. C. \& Fernandes, M. (2017). Preditores de desmame ventilatório em pediatria. Cadernos de Pós-Graduação em Distúrbios do Desenvolvimento, 17(2), 32-42. https://dx.doi.org/10.5935/cadernosdisturbios.v17n2p32-42

Universidade Federal do Triângulo Mineiro (UFTM), Empresa Brasileira de Serviços Hospitalares (EBSERH), Ministério da Educação (2016). Fisioterapia na Bronquiolite Viral Aguda (POP). Unidade de Reabilitação do http://www2.ebserh.gov.br/documents/147715/0/Fisioterapia+na+bronquiolite+viral.pdf/05e01613-e579-4ead-a6e3-85f447b9a6ff

Elm, E., Altman, D. G., Egger, M., Pocock, S. J., Gøtzsche, P. C., Vandenbroucke, J. P., \& STROBE Initiative (2007). The Strengthening the Reporting of Observational Studies in Epidemiology (STROBE) statement: guidelines for reporting observational studies. Lancet (London, England), 370(9596), $1453-1457$. 10.1016/S0140-6736(07)61602-X. 